\title{
The Application of Psychology in Literary Creation
}

\author{
Wenzhuo Dong \\ Yantai Institute of Technology, Yantai 251700, Shandong, China \\ DOI: $10.32629 /$ jher.v2i6.568
}

\begin{abstract}
Creation of literary is derived from people's thinking activities, which is an art that reflects the inner world of writers with language as the carrier. Psychology is a science that studies the occurrence, development and activity rules of psychological phenomena, as well as a broad subject. With the development of the times and the research of many scholars, the relationship between psychology and literature is more and more obvious, showing the characteristics of mutual interpretation and interdependence. Through the purification theory and psychoanalysis theory in psychology, the author further expounds the importance of psychology in literary research and the application of psychology in modern literary creation.
\end{abstract}

Keywords: psychology, literary creation, relationship, importance, application

\section{Introduction}

The relation between psychology and literature can be traced back to the "purification theory" proposed by Aristotle, an ancient Greek scholar. "Purification theory" proposed that the interpretation of tragedy can arouse the audience's deep feelings of compassion and fear, and be purified, so that the audience can obtain a harmless pleasure, and then achieve some moral education. Obviously, "purification theory" on the surface reflects that tragedy can make the audience feel pity, relieve and resolve the depressed mood, and restore the audience's mood calm through emotional catharsis and indulgence, so as to achieve spiritual cleansing. As a matter of fact, if purification theory is extended, the psychological connection between literary works and audience will be realized. And when the audience is watching literary works, a certain plot of the literary works inspires the audience's resonance or sympathy, which leads to a series of psychological fluctuations and thinking of the audience, or solves the puzzle of the audience for a long time, or makes the audience realize enlightenment in the confusion, so as to eliminate the psychological anxiety and loneliness of the audience The sense of melancholy liberates the heavy sense of depression in the heart of the audience and plays a role of purifying the heart

\section{Evaluation of literary works}

How to evaluate a literary work to be good or bad? In other words, can a yardstick be constructed to judge a literary work? This is a question in the minds of many scholars and a controversial issue in the field of literature research. At present, the argument and trend in the field of literature, on the one hand, pursue the perfection of works, requiring creators to use the knowledge of literature theory, literature history, aesthetics, linguistics and rhetoric in the process of literary creation. On the other hand, it seems that most literary works fail to achieve this, which gives rise to many literary critics. It goes without saying that this point is unattainable. As we all know, literary works can be classified as works of art, and each work of art has its own unique beauty. Is there a definition of beauty? Beauty has no definition! People's different cognition and ways of thinking indirectly lead to people's different aesthetics. Maybe he thinks this literary work is beautiful, while I think it is not. There is a common character among them. Any literary work that can make someone feel beautiful must arouse his inner resonance, or make him think about it, and achieve the role of "purifying the heart" in "purifying theory". Had he been asked to judge this work of literature, he would no doubt have given it a favourable appraisal.

Pursuant to the above, the so-called good literature undoubtedly touches the audience's heart and provides them with some help, either psychologically or in life. In order to create good literary works, the creators of literary works need to go deep into the society, understand the real life and inner world of more people, find out the common problems they encounter in life, the common psychological problems, and the common experiences in life, or the common events of the times. . It's not hard to understand, for example the 2020 epidemic, an event that occurred in the course of the development of this era that is also an experience shared by many. Then from this aspect of literary creation, it is easy to arouse the resonance of the audience, so that the audience in the appreciation of literary works caused the migration of their thoughts, inspired their inner feelings, to a certain extent, to purify their inner role. 


\section{The relationship between psychology and literature and the application of psychology in literary creation}

With the development of the times and the research of many scholars, the psychoanalysis school and the birth of collective unconsciousness theory have further brought psychology and literature closer. The psychoanalysis theory proposed by Freud divides the psychological activities of artists in the process of creation into three levels: subconscious, pre-conscious and conscious. Freud pointed out that the essence of literary and artistic creation activities is the subconscious activities, literary and artistic creation are motivated by people's subconscious and sexual instinct, is the sublimation of id, literature and art is a creative process will release pent-up desire and impulse deep layers of consciousness, make the author cannot satisfy the instinctive desire expressed in the form of art. It is pointed out that when artists create art, flying freely in the three psychological fields of consciousness, pre-consciousness and subconscious will be conducive to romantic and profound works. This theory not only shows the importance of unconsciousness and instinct in artistic creation, but also further indicates that psychology plays a crucial role in literary creation.

In this regard, his followers, Swiss psychologist Carl Jung, also pointed out in Psychology and Literature that psychology can not only study the occurrence, development and activity rules of psychological phenomena, but also carry out a series of literary studies in the field of literature. It is well known that human psychology is the mother of all science and art. It is also the source of all literary works. Both the ups and downs of the author's psychological process in creation and the surging psychological changes reflected by readers in appreciation are the contents of psychology. Thus, on the one hand, psychological research can be used to explain the reasons for the formation of literary works, and on the other hand, various factors of literary creativity can be revealed through the study of literary works. This not only objectively shows the inseparable relationship between psychology and literature, but also shows the characteristics of mutual explanation and interdependence between psychology and literature.

Before interpreting the application of Freud's psychoanalysis theory in literary creation, we should first clarify what is the subconscious, pre-consciousness and consciousness, which is also an important content of Freud's "psychoanalysis theory".

The subconscious, also known as the unconscious, is the mental activity that is suppressed and not realized under consciousness and pre-consciousness, and represents the deepest, most secret and most primitive psychological energy of human beings. The subconscious is working in secret all the time. It is the subconscious mind that dominates the whole of human psychology and behavior, and becomes the source of all human behavior and attempts. But the subconscious mind is often locked up, because the subconscious mind has a certain primitiveness, so there must be some characteristics of the subconscious mind that are savage, antisocial, and deviant from reality

Pre-consciousness is also called subconscious, which is connected with both consciousness and subconscious, and is an intermediary mechanism to regulate consciousness and unconsciousness. Preconsciousness is something that can be recalled and called to waking consciousness, and therefore it is linked to both consciousness and the unconscious, making it possible to transform the subconscious into consciousness. However, its role is more reflected in preventing the subconscious from entering consciousness, it plays a "check" role, the vast majority of the subconscious full of instinct impulse is controlled by it, can not become pre-consciousness, let alone into consciousness.

Consciousness refers to conscience, and all psychological activities that one can perceive are consciousness, which belongs to the surface layer of human psychological structure. It perceives the realistic environment and stimulation of the outside world, and reflects and summarizes the rational content of things in language and other ways after the "audit" of the subconscious mind.

In order to facilitate the understanding and deeper understanding of the subconscious, subconscious and consciousness, we introduce the id, ego and superego proposed by Freud in the "psychoanalysis theory". Simply speaking, the ego follows the pleasure principle and represents desire, which follows the "reality principle" and represents the awakening and existence of consciousness. The superego follows "moral principles" and is the judgment of conscience and morality. To take an easy to understand example, I was in class when I suddenly got hungry for bread. In accordance with my happiness principle, I should have left class and gone to the dormitory to eat bread. At this point, following the "reality principle", the ego psychology comes out to "negate" the id psychology: as a student, it is against the classroom discipline to leave the classroom arbitrarily, so we cannot leave the classroom to eat bread in the dormitory. Finally, superego psychology comes out to "reconcile" ego psychology and ego psychology: class is over immediately, and then insist, and so on class is over and then go to the dormitory to eat bread. Thus, in this process, id is the source of a series of psychological activities and behaviors in the beginning. As a "prosecutor" connecting the preceding and the following, ego inhibits ego for a certain period of time, and finally superego considers ego and meets the needs of id. By substituting the subconscious, pre-conscious, and conscious mind with the ego, and superego mind, it is easy to understand the subconscious mind and to understand what follows. 
Based on the above mentioned, we may consider the subconscious mind as the writer's storehouse before creation. When the writer enters the pre-conscious state, he can't help but produce the creative impulse, and finally enters the conscious level to surface his works. These three psychological states affect writers' creation in different degrees. How to apply the "psychoanalysis theory" in the process of literary creation, to better promote literary creation? Nowadays, the field of literature tends to be more and more formal, novel and so on. This requires the author to first stimulate the subconscious, or release the subconscious. Sharp observation, improve imagination. Literary creation is inseparable from observation and association. Only by observing the characteristics of things and fully associating, can we stimulate the "suppressed" subconscious mind. One kind of subconscious mind is the author's own life perception, emotional cognition and so on, and the content created by it is familiar and understandable. The other is deep imagination, the content created by it and what it involves are not often known, and the works created by it may be fictional and unreal. Either can be the inspiration for literary creation, prompting the author to create quite creative articles. Secondly, we should improve the pre-consciousness of "control power". Nowadays, more and more works that defy social rationality are not recognized by the public or even suppressed. This requires the author to be fearless, say what you want and forbid what you want before literary creation. To "make rational creations within the bounds of society. " Please defining what you can and can't write about. It's about controlling what is and isn't inspiration. Correct screening of inspirations from the subconscious mind to select inspirations that are compatible with social development and acceptance. Finally, improve the process of changing consciousness into words. It is not difficult to turn consciousness into words, but it is very difficult to turn consciousness into words, to achieve the effect of "I think I write my heart by hand". Writer should fully experience in the process of creation thinking from heart in their own creation consciousness and inner world to make the article receive the biggest degree of sublimation, so as to make the readers appreciate the works can be deep and thorough understand the author's thoughts and ideas, so as to achieve the effect of net "heart".

\section{Conclusion}

It not only confirms the important role of psychology in the process of literary creation, but also further explores the application of psychology in literary creation.

\section{Acknowledgments}

Dream is born with a strong magnetic field, tempting every unwilling to ordinary friends. I am not a liberal arts student, but a science student. I abandon the study of physical science to study arts, surmounting all obstacles. I published many papers from general periodicals to international English periodicals, from essays to essay. Now look back this, all the way scenery is really very beautiful, although there are too many helpless and lost. Despite questioned and ridiculed, i will bear the time when i put all my devotion for hardworking. I have never been proud of any one of my works. Dreams are endless. You and I will always be followers. However, I'm proud of my experiences, and I'm very grateful for them. They taught me a lot. Falling down taught me how to get back up. Disrespect from others enable me to be strong in confronting pressure in a calm manner. There are innumerable twists and turns along the way. First of all, I want to thank my parents for their support and dedication. Secondly, I would like to give my appreciation to my beloved partner Duan Siqi from Sichuan Conservatory of Music for his warm companionship and encouragement when I was at my lowest ebb. Finally, I would like to express my special thanks to my mentor, Chen Fengjie in Beijing, who has witnessed my growth along the way. Thanks also go to Lei Mengmeng, who has always been so caring. In fact, there are many people i would like to show appreciation, please forgive me not to write your names, but I will always remember in my heart! I hope I can create more achievements on the way of literature. I wish all of you peace and contentment!

\section{References}

[1] Carl Gustav Jung, translated by Feng Chuansuke. Psychology and literature[M]. Yilin Press, 2014, 03.

[2] Gu Wen. Several Important viewpoints in Freud's Literary Thought[A]. Calvin S. Hall, et al. Freud and Literature [C]. Changsha: Hunan Literature and Art Publishing House, 1986.

[3] Norman N. Holland. Postmodern Psychoanalysis [M]. Shanghai: Shanghai Literature and Art Publishing House, 1995.

[4] Carl Gustav Jung. Psychology and Literature [M]. Yilin Press: 2014.

[5] Wang Fang. Aristotle's tragedy "purification theory" [J]. Popular Literature And Art: Academic Edition, 2014, 0(21): 31-31.

[6] Zhu Liyuan, Yuan Xiaolin. Modern Interpretation of Aristotle's theory of tragic purification [J]. Tianjin Social Sciences, 2008(2): 116-121. 